\title{
Anatomical traps for arteriovenous fistula creation
}

\author{
Z.M. Ziętek ${ }^{1,2}$ \\ 'Department of General Surgery and Transplantology, Pomeranian Medical University, Szczecin, Poland \\ ${ }^{2}$ Department of Normal and Clinical Anatomy, Pomeranian Medical University, Szczecin, Poland
}

[Received: 7 May 2020; Accepted: 16 June 2020]

Background: The risk of complications in undisclosed vascular variability appears relatively likely. Therefore, it is important to assess the probability of encountering anatomical-topographic variability in the venous system of the upper limb. The catalogue of patterns of the upper limb venous system seems to be unlimited and should therefore be constantly updated. The aim of the study was to explore the venous system of upper extremity and discuss some problems that would be encountered with the formation of an arteriovenous fistula.

Results: In 17 (85\%) explored upper limbs, the venous system showed a pattern similar to the reports already described. But in (15\%) 3 of them, the venous system showed certain differences in relation to the accepted anatomical textbooks. Especially in one of them the anatomical variant of basilic and cephalic vein contrasted distinctly with the other veins. Based on the revealed anomalies, a statistical analysis of the probability of occurrence of any anatomical variant and the risk of complications associated with fistula creation was conducted. Even on such small group an assessed probability of anatomical variability of the upper limb venous system was statistically significant at $p<0.0244$ (odds ratio 0.0828 ; 95\% confidence interval 0.0095-0.7252).

Conclusions: The probability of any anatomical-topographic variability in the venous system of the upper limb should be considered as statistically significant. Only intense anatomical dissections would undoubtedly help to avoid some anatomical traps and then minimise some complications in the creation of arteriovenous fistulas. (Folia Morphol 2021; 80, 2: 467-470)

Key words: veins, upper limb, anatomy variant, arteriovenous fistula, complications

\section{INTRODUCTION}

Since the development of the first arteriovenous access, many reports have appeared, not always flattering it $[5,9,10,13,15,18]$. Particularly risky is an undisclosed variability of vascular system of the upper limb which could discourage surgeons from using a classic approach [1, 11-13].
In many published reports, rates of arteriovenous fistula complications were assessed [1]. Most of them included aneurysm, infection, terminal ischaemia syndrome, thrombosis or venous hypertension $[1,17]$. It seems that all of this could have contributed to the collapse of an interest in the creation of arteriovenous fistulas [11]. So at the end of the 70s, other alternative

Address for correspondence: Prof. Z. Ziętek, Department of General Surgery and Transplantology, Pomeranian Medical University, Al. Powstańców Wielkopolskich 72, 70-111 Szczecin, Poland, tel: +48 91 4661480, mobile: 503502735, e-mail: zzietek@poczta.onet.pl 
vascular access approaches began to be used [4, 12, $17,18]$. However, longer observations of the results revealed them as more dangerous with even more severe complications $[1,4,11,12,17,18]$.

Many authors emphasized that complications associated with fistula formation started with technical problems related to vascular topography $[9,11]$. The traditional anatomy textbooks offer little description of the upper limb veins and are particularly silent in regards to their variations. The number of patterns seems to be unlimited and therefore should be constantly updated. Continuous updating and, more importantly, a permanent reminder of those already discovered would be particularly useful in vascular procedures, including arteriovenous fistulas [3, 7, 9]. Arteriovenous fistula is again becoming a popular vascular access procedure [3]. There are many reasons, and one of them is an intensive anatomical work that broadens knowledge about the vascular system of the upper limb $[3,6,7,9,10,15]$. Classic arteriovenous fistula still seems to be a good method associated with a lower rate of complications compared to other methods [1, 4]. All of that has resulted in a slow return to classic arteriovenous fistulas [1, 3].

Despite of our modest anatomical material of the upper limbs, we would like to present some revealed variants of the venous system. In addition, some possible anatomical traps in the creation of an arteriovenous fistula were analysed.

\section{MATERIALS AND METHODS}

The material was consisted of 20 preparations of the upper limb taken from 10 deceased ( 6 men and 4 women). The anatomical explorations were conducted at the Faculty of Normal and Clinical Anatomy of the Pomeranian Medical University in Szczecin. The cadavers were preserved and stored in a solution of formalin, glycerine and ethyl alcohol. Among the cadavers were 6 males and 4 females. The registered age on the day of their death was 67-81 years. The body storage period was $10-20$ years. The upper limbs were without visible genetic deformities or previous surgery. Apart from typical sectional instruments such as scalpels, tweezers and raspators, a magnifying camera was also used, which was particularly useful in the exploration of small blood vessels. For clarity of photographic documentation, the dissected blood vessels have been coloured. Then the dissected upper limbs were photographed for the scientific purposes and then allocated for educational programme.

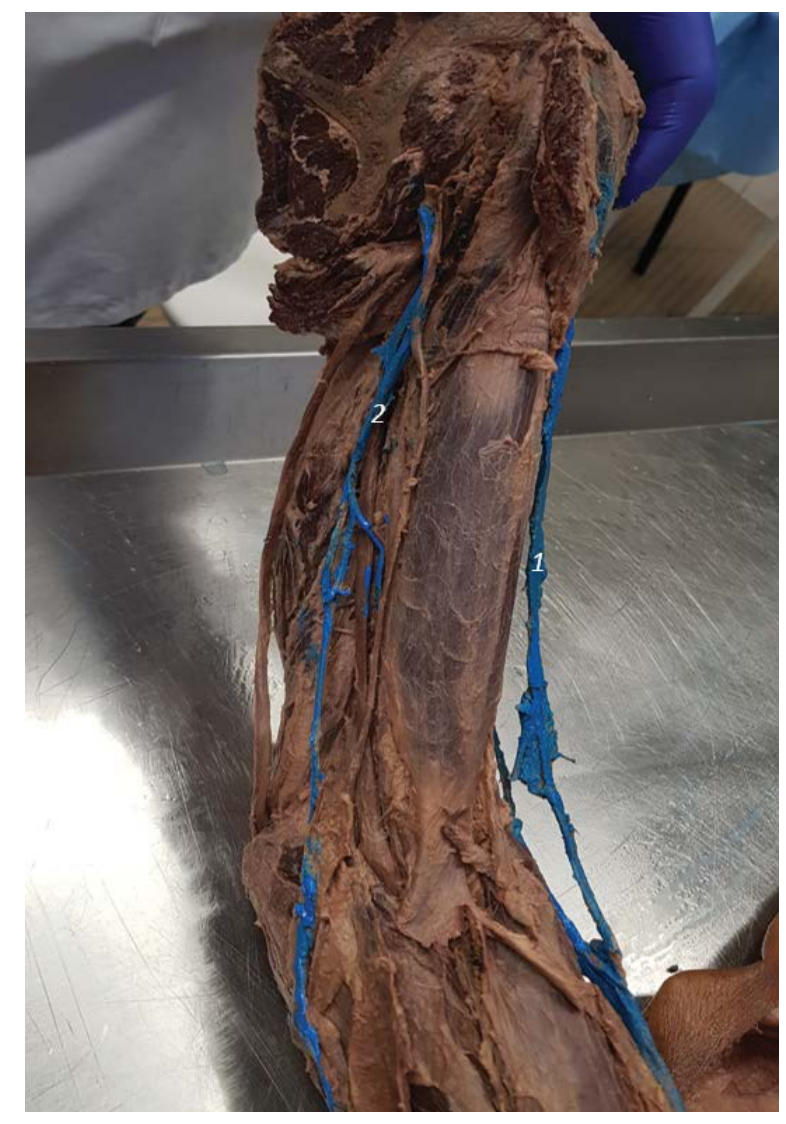

Figure 1. The correct picture of the cephalic vein (1) and the basilic vein (2).

\section{RESULTS}

The main intention of this exploration was to educate students. But during the preparation of the upper limbs, some variants of the venous system were discovered, which have not yet been described in anatomy textbooks.

In 17 (85\% of all) upper limbs, the venous system showed a pattern similar to the reports already described (Fig. 1). But in 3 (15\%) of them, the venous system showed certain dissimilarities in relation to the accepted anatomical textbooks.

Especially in one of them the topography of the basilic and cephalic vein contrasted significantly with the others (Fig. 2). At the beginning the both veins ran along both sides of the forearm, but instead of climbing on the arm, they both approached the cubital fossa, where they connected to the deep venous system. The next unusual thing was the brachial vein. Usually in the cubital fossa can be found two brachial veins, but unexpectedly there was only one. Only this one brachial vein was formed from the 


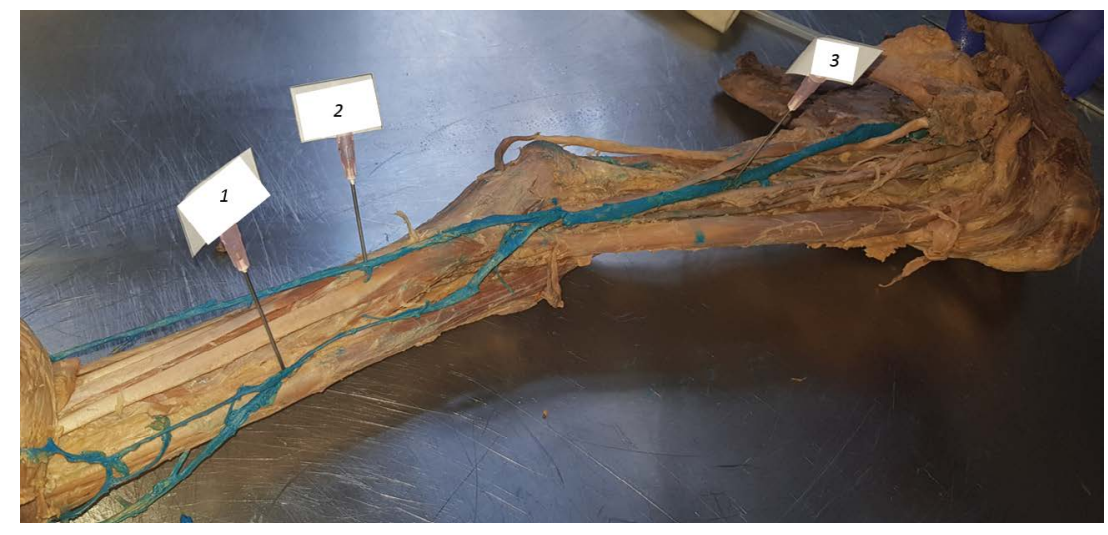

Figure 2. The correct picture of the cephalic vein (1) and the basilic vein (2) and brachial vein (3). connection of the superficial and deep veins. This was finally confirmed by further exploration of the upper limb. To the surprise, the estimated probability of occurrence of anatomical variability of the venous system of the upper limb was statistically significant at $p<0.0244$ (odds ratio $0.0828 ; 95 \%$ confidence interval 0.0095-0.7252). In extrapolation analysis it can be stated that about $90 \%$ of fistulas would not have encountered any topographic diversity during surgery, but every tenth may already occur. This would mean that there may really be topographic difficulties with the venous system in creating an arteriovenous fistula.

\section{DISCUSSION}

The knowledge about anatomical variabilities of upper limb venous system is intensively updated, but in clinical practice still encounters some limits $[2,3,7-10,14,16]$.

Anatomical exploration of human body is a challenge for both anatomists and, especially, clinicians, because undiscovered variations can cause many problems in their daily medical practice $[1,4,9,12,13]$.

In addition to updates, it should be reminded about already discovered patterns. It seems to be crucial for the successful treatment $[3,7,9]$.

Although anatomy departments all over the world suffer from a body deficiency, intensive anatomical dissections have been conducted and undoubtedly contributed to restored priorities of arteriovenous fistulas $[3,6,8,10]$.

We did not expect that in our very small group of limbs we would encounter some anomalies of deep and superficial veins. Indeed, in 17 preparations of the upper limbs, the topography of venous vessels was consistent with the classic descriptions of textbooks. The basilic and cephalic vein runs up along both side of forearm. The basilic one comes into arm on the medial side of it, and in half of arm dives more proximally to join one of two brachial veins near the axilla. But cephalic vein runs higher to join the axillar vein in the deltopectoral triangle. It can be supposed that in theses anatomical variations the creation of an arteriovenous fistula would not encounter any anatomical or topographic difficulties. But in $3(15 \%)$ limbs the topography of brachial, basilic and cephalic vein did not coincide with the descriptions of textbooks and literary reports. Especially in one limb it was completely different, which is the subject of this case report. Searching the literature data, a similar variant was found, which has already been described and classified as very rare [14]. This prompted us to re-present this variant, but in the aspect of creating arteriovenous fistulas. The accidental ligation of such an unpaired brachial vein would stop the outflow of blood and develop some complications such as oedema or even phlegmasia cerulea dolens. Therefore, we would like to remind of this and anticipate some problems in creating of fistula $[1,14,17]$.

Our variant could be described as the second case report. However, in our opinion, more important than report numbering is whether a particular case is really rare, as is supposed. The disclosure of a similar variety on our small anatomical material may indicate that this variant should not be considered very rare. Especially it is important in creation of arteriovenous fistula in the middle arm (middle arm fistula [MAF]). This method (MAF) is rapidly becoming a more common vascular access procedure, especially in so called difficult arteriovenous fistulas [16]. This should remind surgeons about this topography pattern when they plan to form an arteriovenous fistula in the arm with basilic vein transposition $[2,3,6,15]$. The presented variability seems particularly interesting in the context 
of possible complications after the creation of MAF $[1,17]$. The clinical report of Kaiser et al. [9] confirms the possibility of occurrence of some complications with MAF creation in atypical junction to the basilic vein with the unpaired brachial vein.

\section{CONCLUSIONS}

Because of the likelihood of variability in the venous system of the upper limb, examining it before surgery would contribute to avoiding some difficulties and pitfalls. These preliminary results of the upper limb venous system require further investigations.

\section{REFERENCES}

1. Al-Jaishi AA, Liu AR, Lok CE, et al. Complications of the arteriovenous fistula: a systematic review. J Am Soc Nephrol. 2017; 28(6): 1839-1850, doi: 10.1681/ASN.2016040412, indexed in Pubmed: 28031406.

2. Altıparmak B, Korkmaz Toker M, Uysal Ai, et al. Double axillary vein variation diagnosed with ultrasound guidance during infraclavicular nerve block intervention. BMJ Case Rep. 2019; 12(1), doi: 10.1136/bcr-2018-227495, indexed in Pubmed: 30696646.

3. Anaya-Ayala JE, Younes HK, Kaiser CL, et al. Prevalence of variant brachial-basilic vein anatomy and implications for vascular access planning. J Vasc Surg. 2011; 53(3): 720-724, doi: 10.1016/j.jvs.2010.09.072, indexed in Pubmed: 21144691.

4. Astor BC, Eustace JA, Powe NR, et al. Type of vascular access and survival among incident hemodialysis patients: the Choices for Healthy Outcomes in Caring for ESRD (CHOICE) Study. J Am Soc Nephrol. 2005; 16(5): 1449-1455, doi: 10.1681/ASN.2004090748, indexed in Pubmed: 15788468

5. Brescia MJ, Cimino JE, Appell K, et al. Chronic hemodialysis using venipuncture and a surgically created arteriovenous fistula. N Engl J Med. 1966; 275(20): 1089-1092, doi: 10.1056/NEJM196611172752002, indexed in Pubmed: 5923023.

6. Fontaine $\mathrm{C}$. Some help for literature study in anatomical variation reports. Surg Radiol Anat. 2001; 23(5): 293-294, doi: 10.1007/s00276-001-0293-6, indexed in Pubmed: 11824125.

7. Griffioen FMM, Drukker J, Hoogland PVJM, et al. General plan anatomy. Objectives of the teaching of anatomy/ /embryology in medical curricula in the netherlands. Eur J Morphol. 1999; 37(4-5): 288-325, doi: 10.1076/ ejom.37.4.288.4721.

8. Jones DG, Dias GJ, Mercer S, et al. Clinical anatomy research in a research-driven anatomy department. Clin Anat. 2002; 15(3): 228-232, doi: 10.1002/ca.10017, indexed in Pubmed: 11948960.

9. Kaiser CL, Anaya-Ayala JE, Ismail N, et al. Unrecognized basilic vein variation leading to complication during basilic vein transposition arteriovenous fistula creation: case report and implications for access planning. Eur J Vasc Endovasc Surg. 2010; 39(5): 627-629, doi: 10.1016/j. ejvs.2010.01.011, indexed in Pubmed: 20172752.

10. Lee H, Lee SH, Kim SJ, et al. The clinical anatomy of the cephalic vein in the deltopectoral triangle. Folia Morphol. 2008; 67: 72-77.

11. Lemson MS, Tordoir JH, Daemen MJ, et al. Intimal hyperplasia in vascular grafts. Eur J Vasc Endovasc Surg. 2000; 19(4): 336-350, doi: 10.1053/ejvs.1999.1040, indexed in Pubmed: 10801366.

12. Miller A, Hölzenbein TJ, Gottlieb MN, et al. Strategies to increase the use of autogenous arteriovenous fistula in end-stage renal disease. Ann Vasc Surg. 1997; 11(4): 397-405, doi: 10.1007/s100169900068, indexed in Pubmed: 9236998.

13. Quinton W, Dillard D, Scribner BH, et al. Cannulation of blood vessels for prolonged hemodialysis. Trans Am Soc Artif Intern Organs. 1960; 6(1): 104-113, indexed in Pubmed: 13738750.

14. Sadeghi A, Setayesh Mehr M, Esfandiari E, et al. Variation of the cephalic and basilic veins: A case report. J Cardiovasc Thorac Res. 2017; 9(4): 232-234, doi: 10.15171/ jcvtr.2017.40, indexed in Pubmed: 29391938.

15. Sandhu NPS, Sidhu DS. Mid-arm approach to basilic and cephalic vein cannulation using ultrasound guidance. $\mathrm{Br}$ J Anaesth. 2004; 93(2): 292-294, doi: 10.1093/bja/aeh179, indexed in Pubmed: 15194622.

16. Sanudo JR, Vazquez R, Puerta J. Meaning and clinical interest of the anatomical variations in the $21^{\text {st }}$ century. Eur J Anat. 2003; 7(S1): 1-3.

17. Tellis VA, Veith FJ, Soberman RJ, et al. Internal arteriovenous fistula for hemodialysis. Surg Gynecol Obstet. 1971; 132(5): 866-870, indexed in Pubmed: 4929209.

18. Wijeyaratne SM, Kannangara L. Safety and efficacy of electrospun polycarbonate-urethane vascular graft for early hemodialysis access: first clinical results in man. J Vasc Access. 2011; 12(1): 28-35, doi: 10.5301/jva.2011.6278, indexed in Pubmed: 21279948. 